\title{
PCR-based detection of Babesia bovis and Babesia bigemina in their natural host Boophilus microplus and cattle
}

\author{
T.C.G. Oliveira-Sequeira ${ }^{a, *}$, M.C.S. Oliveira ${ }^{b}$, J.P. Araujo Jr. ${ }^{c}$, A.F.T. Amarante ${ }^{a}$ \\ ${ }^{a}$ Departamento de Parasitologia, Instituto de Biociências, Unesp, Botucatu, SP 18618-000, Brazil \\ ${ }^{\mathrm{b}}$ Empresa Brasileira de Pesquisa Agropecuária - Embrapa - CPPSE, São Carlos, SP, Brazil \\ ${ }^{\mathrm{c}}$ Departamento de Microbiologia e Imunologia, Instituto de Biociências, Unesp, Botucatu, SP, Brazil
}

Received 9 August 2004; received in revised form 10 September 2004; accepted 12 September 2004

\begin{abstract}
PCR and nested-PCR methods were used to assess the frequency of Babesia bovis and Babesia bigemina infection in Boophilus microplus engorged females and eggs and in cattle reared in an area with endemic babesiosis. Blood and the engorged female ticks were from 27 naturally infested calves and 25 crossbred cows. The frequency of both Babesia species was similar in calves and cows $(P>0.05)$. Babesia bovis was detected in $23(85.2 \%)$ calves and in 25 (100\%) cows and B. bigemina was detected in $25(92.6 \%)$ calves and in 21 (84\%) cows. Mixed infections with the both Babesia species were identified in 42 animals, 21 in each age category. Of female ticks engorged on calves, $34.9 \%$ were negative and single species infection with $B$. bigemina $(56.2 \%)$ was significantly more frequent $(P<0.01)$ than with $B$. bovis (4.7\%). Most of the females (60.8\%) engorged on cows did not show Babesia spp. infection and the frequency of single $B$. bovis infection $(17.6 \%)$ was similar $(P>0.05)$ to the frequency of single $B$. bigemina infection (15.9\%). Mixed Babesia infection was lower $(P<0.01)$ than single species infection in female ticks engorged either in cows (5.7\%) or in calves (4.3\%). An egg sample from each female was analysed for the presence of Babesia species. Of the egg samples from female ticks infected with B. bovis, 26 (47.3\%) were infected while from those from female ticks infected with B. bigemina $141(76.6 \%)$ were infected $(P<0.01)$. The results showed that although the frequency of both species of Babesia was similar in calves and cows, the infectivity of B. bigemina was higher to ticks fed on calves while to those ticks fed on cows the infectivity of both Babesia species was similar.
\end{abstract}

(C) 2004 Australian Society for Parasitology Inc. Published by Elsevier Ltd. All rights reserved.

Keywords: Babesia bovis; Babesia bigemina; Boophilus microplus; Brazil; Polymerase chain reaction

\section{Introduction}

In Latin America, bovine babesiosis is due to Babesia bovis and Babesia bigemina, which are exclusively transmitted by the tick Boophilus microplus. Most of the Brazilian territory is endemic for B. microplus. While the condition of endemic stability is the most common for both Babesia species, areas of enzootic instability have been identified (Vidotto et al., 1997).

Information about the epidemiology of babesiosis, especially on the dynamics of transmission by the vector ticks is essential for the elaboration of adequate control

\footnotetext{
* Corresponding author. Tel.: +55 14 38116239; fax: +55 1438153744 .

E-mail address: sequeira@ibb.unesp.br (T.C.G. Oliveira-Sequeira).
}

strategies (Morzaria et al., 1992). Thus, in addition to information about the prevalence of these parasitic diseases in vertebrate hosts, the detection and specific discrimination of Babesia species in ticks is of fundamental importance.

Microscopic techniques for blood examination remain the most appropriate for the diagnosis of acute babesiosis, but the low sensitivity of these methods does not permit its use in epidemiological studies in which it is necessary to identify carrier animals (Almeria et al., 2001). Several serological methods standardized for the diagnosis of babesiosis have been extensively employed in epidemiological field studies. Among the drawbacks of these techniques is the occurrence of cross-reactions between B. bovis and B. bigemina (Passos et al., 1998) and the lack of discrimination between previous exposure and current infections (Wagner et al., 1992). 
The main drawbacks for the microscopic detection of Babesia spp. in haemolymph of adult ticks, and in tick egg and larval squashes are the low sensitivity and the difficulty of differentiating between the species involved (Guglielmone et al., 1996, 1997).

The application of PCR-based tests to the study of the epidemiology of babesiosis is still incipient, but characteristics of high sensitivity and specificity have been verified by several authors (Fahrimal et al., 1992; Figueroa et al., 1992; Smeenk et al., 2000; Almeria et al., 2001) for the detection of infection both in the vertebrate hosts and ticks.

Because low level infection as well as transmission and transmissibility are important aspects in epidemiology of babesiosis, PCR-based techniques were used in order to estimate the rate of B. bovis and B. bigemina infection in blood from cross-bred dairy cattle of two age ranges and in B. microplus females and eggs collected from these animals.

\section{Materials and methods}

\subsection{Animals}

The study was conducted on 52 crossbred (Bos indicus $\times$ Bos taurus) dairy animals ( 25 cows aged more than 3 years and 27 calves aged 1-4 months) naturally infested with $B$. microplus. All animals belonged to a herd reared at the 'Centro de Pesquisa de Pecuária do SudesteEMBRAPA', located in São Carlos, SP, Brazil (latitude $22^{\circ} 01^{\prime}$ South and longitude $47^{\circ} 53^{\prime}$ West), with a subtropical climate.

\subsection{Blood samples and B. microplus collections}

All animals were sampled only once and blood and B. microplus females were simultaneously collected on three occasions from November 2000 to January 2001. Blood samples from the jugular vein were collected into tubes containing EDTA for DNA extraction and samples from ear vessels were obtained for the preparation of thin blood smears, stained with Giemsa, for the determination of parasitemia.

All B. microplus females more than $4.5 \mathrm{~mm}$ (Hermans et al., 1994) were collected from each animal to determine the parasite burden. After the counts, 10 fully engorged females from each animal were individually placed on hollow polyethylene plates and incubated at $27 \pm 1{ }^{\circ} \mathrm{C}$ and $85-86 \%$ relative humidity for collection of eggs.

On the fifteenth day of oviposition, each female tick was transferred to a labelled microtube, and each mass of eggs laid between the 6th and 15th day of oviposition (Mahoney and Mirre, 1977) was collected and transferred to another microtube. The female tick and egg samples were stored in a freezer at $-80{ }^{\circ} \mathrm{C}$ for later DNA extraction.

\subsection{DNA extraction and PCR and $n P C R$ procedures}

DNA was extracted from a blood sample aliquot of $300 \mu$ l using the GFX $^{\mathrm{TM}}$ Genomic Blood DNA Purification kit (Amershan Bioscience) according to manufacturer's instructions.

For DNA extraction from the B. microplus females, each frozen specimen was individually macerated in a microtube to which $10 \mu \mathrm{l}$ of buffer was added $(10 \mathrm{mM}$ Tris- $\mathrm{HCl}$, $1 \mathrm{mM}$ EDTA and 5\% Triton X-100, $\mathrm{pH} 8.5)$ and incubated for $15 \mathrm{~min}$ at room temperature. In sequence, $20 \mu \mathrm{l}$ of proteinase $\mathrm{K}$ solution $(20 \mu \mathrm{g} / \mathrm{ml}$ in $10 \mathrm{mM}$ Tris- $\mathrm{HCl}$, $\mathrm{pH}$ 8.0) was added, the preparation was incubated in a water bath for $4 \mathrm{~h}$ at $56{ }^{\circ} \mathrm{C}$, and for $10 \mathrm{~min}$ at $70{ }^{\circ} \mathrm{C}$. After incubation, DNA extraction was performed using the GFX $^{\mathrm{TM}}$ Genomic Blood DNA Purification kit according to the same protocol as used for the blood samples.

For DNA extraction from egg samples, $20 \mathrm{mg}$ samples of eggs were weighed out and placed in a microtube and washed with buffer (10 mM Tris-HCl, $1 \mathrm{mM}$ EDTA, 5\% Triton $\mathrm{X}-100, \mathrm{pH} 8.5)$. After centrifugation at $5000 \times g$ for 2 min, the supernatant was discarded and the eggs were macerated with the aid of a glass rod. A solution of Proteinase $\mathrm{K}(20 \mu \mathrm{l})$ was added to the egg macerate and the preparation was incubated overnight at $56{ }^{\circ} \mathrm{C}$. After incubation, the same procedures as described for the female ticks were adopted.

PCR and nested-PCR (nPCR) techniques were used for the amplification of B. bovis and B. bigemina DNA using the primer sequences described by Figueroa et al. (1993). Only PCR-negative blood samples were submitted to nPCR, whereas all samples extracted from female ticks and eggs were submitted to nPCR.

PCR was performed in a $25 \mu \mathrm{l}$ solution containing $10 \mathrm{mM}$ Tris-HCl; $50 \mathrm{mM} \mathrm{KCl} ; 1.5 \mathrm{mM} \mathrm{MgCl}$; $1.5 \mathrm{U}$ TaqDNA-polymerase (Amersham Bioscience); $0.2 \mathrm{mM}$ of each nucleotide (Amersham Bioscience); $10 \mathrm{pm}$ of each primer and $5 \mu \mathrm{l}$ of DNA samples. The same buffer at the same concentrations and $2 \mu \mathrm{l}$ of the previously PCR amplified products were used for nPCR.

Purified samples of $B$. bovis and B. bigemina, kindly provided by Drs Raul H. Kessler and Cláudio Madruga (CNPGC-Embrapa, Brazil) were used for positive control of PCR and nPCR reactions. Amplification reactions using purified bovine DNA, and purified samples of Anaplasma marginale were performed to test the specificity of the primers. For the control of contamination, a tube containing no DNA sample was included in each reaction batch.

The amplification products were submitted to electrophoresis on $1.5 \%$ agarose gel containing ethidium bromide. The length of the amplified products was estimated by including a base pair standard (100 base-pair ladder Amersham Biosciences) and the amplified products were visualized with an UV transilluminator. Samples presenting visible bands of approximately 278 base pairs (PCR) or 170 base pairs (nPCR) were considered positive for B. bigemina. 
For B. bovis, PCR positive bands were of 350 base pairs and nPCR positive bands of 290 base pairs. Three B. bigemina-amplicons and three B. bovis-amplicons, respectively from blood, female tick and egg samples were sequenced and were confirmed to correspond to the GenBank accessions S45366 (ApeI - AvaI restriction fragment of B. bigemina) and AF030061 (rap-1 protein of B. bovis).

\subsection{Estimated analytical sensitivity of $P C R$ and $n P C R$}

PCR and nPCR sensitivity was estimated from a $300 \mu \mathrm{l}$ aliquot of the purified $B$. bovis and B. bigemina samples containing $3 \times 10^{6}$ and $6 \times 10^{6}$ parasitized erythrocytes, respectively. The samples were diluted 15 times by 10 -fold dilutions and submitted to amplification. Sensitivity was calculated considering the number of parasitized erythrocytes detected in the last dilution in which it was possible to identify the bands of the corresponding size for each species.

\subsection{Statistical analysis}

The data obtained from calves and cows concerning blood DNA amplification (PCR and nPCR), and nPCR of eggs and female ticks were compared by the $\chi^{2}$-test. The exact Fisher test was used to compare the data for the blood smears with the data of blood PCR and nPCR using the FREQ procedure of the SAS software (SAS, Institute Inc., SAS/STAT., 1996. User's Guide, version 6.11, 4ed., v.2, Cary, SAS Institute Inc.).

\section{Results}

\subsection{Blood samples}

Estimated analytical sensitivity of PCR and nPCR for B. bigemina corresponded to parasitemias of 0.00003 and $0.0000003 \%$, respectively. For B. bovis, the sensitivity corresponded to parasitemias of $0.000017 \%$ (PCR) and $0.00000017 \%$ (nPCR).

The data concerning the detection of B. bovis and $B$. bigemina in blood samples using blood smears and DNA amplification are presented in Table 1. Merozoites of B. bigemina $(0.1-0.2 \%$ parasitized erythrocytes $)$ and

Table 1

Summary of detected Babesia bovis and Babesia bigemina merozoites (blood smears) and DNA (PCR/nPCR) in blood

\begin{tabular}{lcllll}
\hline & \multicolumn{2}{l}{ Calves $(n=27)$} & & \multicolumn{2}{l}{ Cows $(n=25)$} \\
\cline { 2 - 3 } & $\begin{array}{l}\text { Blood } \\
\text { smear }\end{array}$ & PCR(nPCR) & & $\begin{array}{l}\text { Blood } \\
\text { smear }\end{array}$ & PCR(nPCR) \\
\hline B. bovis & 2 & $2(0)$ & 0 & $2(2)$ \\
B. bigemina & 11 & $3(1)$ & 0 & $0(0)$ \\
B. bovis/B. bigemina & 1 & $20(1) / 14(7)$ & 0 & $17(4) / 14(7)$ \\
\hline
\end{tabular}

Table 2

Number of Boophilus microplus female infected with Babesia bovis and/or Babesia bigemina detected by nPCR in 258 ticks collected from 27 calves

\begin{tabular}{|c|c|c|c|c|}
\hline \multirow{2}{*}{$\begin{array}{l}\text { Calf infec- } \\
\text { tion }(n=27)\end{array}$} & \multicolumn{4}{|c|}{ Female tick infection $(n=258)$} \\
\hline & B. bovis & B. bigemina & $\begin{array}{l}\text { B. bovis/ } \\
\text { B. bigemina }\end{array}$ & Negative \\
\hline B. bovis & 0 & 10 & 1 & 5 \\
\hline B. bigemina & 1 & 27 & 1 & 11 \\
\hline $\begin{array}{l}\text { B. bovis/B. } \\
\text { bigemina }\end{array}$ & 11 & 108 & 9 & 74 \\
\hline Total & 12 & 145 & 11 & 90 \\
\hline
\end{tabular}

B. bovis (less than $0.1 \%$ ) were detected exclusively in the blood smears of calves, with only one of them carrying both species.

Twenty-two of the 23 calf blood samples positive for B. bovis were detected by PCR and one by nPCR, and of the 25 samples positive for B. bigemina, eight were detected by nPCR. Nineteen of the 25 cow blood samples positive for B. bovis were detected by PCR and six by nPCR, and 14 of the 21 samples positive for $B$. bigemina were detected by PCR. The rates of $B$. bovis and B. bigemina infection were similar for the two animal categories $(P>0.05)$, and concomitant infection with the two Babesia species were detected in 21 cows and 21 calves.

\subsection{Tick samples}

The data concerning the detection of B. bovis and/or B. bigemina in B. microplus females according to infection of calves and cows are presented in Tables 2 and 3 , respectively. For female ticks that engorged on calves (258), the number of $B$. bigemina infected females (145) was higher $(P<0.01)$ than the number of females infected with $B$. bovis (12), the number of those with mixed infection with both species (11) as well the number of uninfected females (90). Of the 113 females that fed on the 12 calves with overt B. bigemina parasitemia, $79(70 \%)$ were infected with this species, while of the 145 females that fed on calves without parasitemia, $77(53 \%)$ were infected $(P<0.01)$.

In the female ticks collected from cows, the frequency of B. bovis (43) and B. bigemina (39) infection were similar

Table 3

Number of Boophilus microplus female infected with Babesia bovis and/or Babesia bigemina detected by nPCR in 245 ticks collected from 25 cows

\begin{tabular}{lcccc}
\hline Cow infec- & \multicolumn{5}{l}{ Female tick infection $(n=245)$} \\
\cline { 2 - 5 } tion $(n=25)$ & B. bovis & B. bigemina & $\begin{array}{l}\text { B. bovis/ } \\
\text { B. bigemina }\end{array}$ & Negative \\
\hline B. bovis & 3 & 10 & 1 & 26 \\
$\begin{array}{l}\text { B. bigemina } \\
\text { B. bovis/ }\end{array}$ & - & - & - & - \\
B. bigemina & 40 & 29 & 13 & 123 \\
Total & 43 & 39 & 14 & 149 \\
\hline
\end{tabular}


Table 4

Number of Boophilus microplus egg samples infected with Babesia bovis and/or Babesia bigemina as a function of the origin of the engorged females

\begin{tabular}{llrlrl}
\hline $\begin{array}{l}\text { Engorged } \\
\text { female origin }\end{array}$ & \multicolumn{2}{l}{ Egg samples infection } \\
\cline { 2 - 6 } & B. bovis & B. bigemina & $\begin{array}{l}\text { B. bovis/ } \\
\text { B. bigemina }\end{array}$ & Negative & Total \\
\hline Calves & 10 & 126 & 5 & 86 & 227 \\
Cows & 16 & 15 & 0 & 180 & 211 \\
Total & 26 & 141 & 5 & 266 & 438 \\
\hline
\end{tabular}

$(P>0.05)$, being higher $(P<0.01)$ than the frequency of mixed infection $(14)$ and lower $(P<0.01)$ than the frequency of negative females (149).

The results of DNA amplification of B. bovis and $B$. bigemina in egg samples are presented in Table 4 according to the origin of the female ticks. For females that fed on calves, simple $B$. bigemina infection predominated in the egg samples (126) and for females that fed on cows noninfected egg samples (180) predominated.

The females collected from calves produced a significantly larger number $(P<0.01)$ of egg samples infected with $B$. bigemina (131) than with B. bovis (15), whereas those collected from cows produced similar numbers of egg samples infected with each single species $(P>0.05)$.

No significant association $(P>0.05)$ was observed between the frequency of $B$. bigemina infection in B. microplus eggs and the presence of overt parasitemia in the vertebrate host. Of the 100 egg samples whose females engorged on calves with overt parasitemia, 64 (64\%) were positive, and of the 127 egg samples originating from females engorged on calves without parasitemia 67 $(52.75 \%)$ were positive $(P>0.05)$.

Table 5 shows the number of $B$. microplus egg samples infected with $B$. bovis and/or B. bigemina according to infection of the females that gave origin to them, regardless of the origin of the female ticks. In this evaluation, the 431 data pairs analysed were those for which amplification results were obtained both for the females and their respective egg samples. A close correspondence between female tick results and their respective egg samples was observed only for B. bigemina infected and for negative female ticks. Most of egg samples (61.3\%) from

Table 5

Number of Boophilus microplus egg samples infected with Babesia bovis and/or Babesia bigemina in relation to the species of Babesia detected in the engorged females

\begin{tabular}{llcll}
\hline $\begin{array}{l}\text { Engorged } \\
\text { female infec- } \\
\text { tion }\end{array}$ & \multicolumn{4}{l}{ Egg sample infection } \\
\cline { 2 - 5 } & B. bovis & B. bigemina & $\begin{array}{l}\text { B. bovis/ } \\
\text { B. bigemina }\end{array}$ & Negative \\
\hline $\begin{array}{l}\text { B. bovis } \\
\text { B. bigemina }\end{array}$ & 2 & 8 & 0 & 35 \\
$\begin{array}{l}\text { B. bovis/ } \\
\text { B. bigemina }\end{array}$ & 0 & 95 & 3 & 49 \\
Negative & 16 & 7 & 0 & 14 \\
Total & 26 & 142 & 0 & 162 \\
\hline
\end{tabular}

B. bigemina infected females (155) were also infected, and $77 \%$ of egg samples from negative females (210) were negative. For the females infected with B. bovis (45), $77.7 \%$ of the egg samples were negative, $4.4 \%$ were infected with this species, and no mixed infected egg samples were produced by mixed infected female ticks (21).

\section{Discussion}

This is the first study in which molecular diagnostic techniques were used to investigate the epidemiology of bovine babesiosis in Brazil and in which the rates of infection were assessed simultaneously in the cattle and in the intermediate host tick.

The high frequency of $B$. bovis and B. bigemina infections both in calves and in adult animals indicate a situation of stable endemy (Goff et al., 2002) and are comparable to those detected by immunodiagnosis in different endemic regions in the country (Araújo et al., 1997; Madruga et al., 2001). However, using PCR techniques the detection of specific infection was possible in animals as young as 1 month of age, and the prevalence obtained refers to the presence of current infection and not simply exposure to the protozoon, as is the case when serological methods are used (Wagner et al., 1992).

As expected, the frequency of Babesia infection in cattle detected by DNA amplification methods was significantly higher than that obtained in microscopic examination of blood smears, because the latter method does not detect positive animals in the early phase or in the carrier stage of infection, when the number of circulating parasites is very low (Calder et al., 1996).

The detection of Babesia infection in animals in the early phases of infection and in carrier animals by DNA amplification was a powerful tool for epidemiological investigation, since these animals represent an important source of alimentary infection of B. microplus females (Friedhoff and Smith, 1981), especially if we consider that vertical infection $(=$ continuous transovarial and transtadial infection of all tick stages) does not occur in B. bovis and, although possible for $B$. bigemina, it is much less efficient (Büscher, 1988).

As the methodology used in the present study permitted the detection of current infections both in cattle and in ticks, and especially the discrimination between Babesia species, it was possible to quantitatively assess the contribution of young and adult animals to the induction of B. microplus infection by each Babesia species.

Babesia bigemina were detected more frequently in female ticks that fed on calves $(156 / 258)$ than in those that fed on cows (53/245). In addition, calves with overt $B$. bigemina parasitemia were responsible for a larger number of infected female ticks than calves with negative Giemsa-stained smears. These results agree with previous reports about B. bigemina (Riek, 1964; Callow, 1968) 
and with observations made on other Babesia species (Riek, 1966; Yeruham et al., 2001).

Several authors who investigated the quantitative aspects of Babesia transmission have reported that $B$. microplus females are more frequently infected with B. bigemina than with B. bovis (Riek, 1964, 1966; Mahoney and Mirre, 1971, 1977; Davey, 1981). However, it should be pointed out that these observations were made in experiments in which the ticks were fed on animals aged 4-8 months experimentally infected with one or the other Babesia species. So, the present results agree with these observations only with respect to the females that became infected on calves, in which the frequency of infection with $B$. bigemina (156/258) was higher than the frequency of infection with $B$. bovis (23/ 258). In contrast, in the females engorged on cows, the frequency of $B$. bovis infection (57/245) was similar to the frequency of $B$. bigemina infection (53/245).

With respect to $B$. bovis, the significantly lower number of female ticks that became infected on calves (23/258) compared to those that became infected on cows (57/245) may represent evidence that age-related effects interfere in different ways with the infectivity of the two Babesia species for ticks. If in relation to B. bigemina, the higher rate of infection in the female ticks collected from young animals could be related to a greater parasite density in their blood and the lack of active immunity, the same does not apply to B. bovis for which the number of infected females was smaller for those that fed on young animals. Although there are no data to explain these results, the presence of foetal haemoglobin $(\mathrm{HbF})$ in the calves could represent a possibility since $\mathrm{HbF}$ is considered one of the factors contributing to the high resistance of young cattle against B. bovis infection (Ristic and Levi, 1981). The presence of $\mathrm{HbF}$, as well as some human haemoglobinopathies (Pasvol et al., 1976), is also related to greater resistance to infection with Plasmodium falciparum. Furthermore, significant differences were observed in the rate of infection of Anopheles mosquitoes feeding on individuals with different haemoglobin phenotypes (Robert et al., 1996). In addition to this circumstantial evidence suggesting that $\mathrm{HbF}$ may interfere with the transmission of B. bovis from calves to the female ticks, it should be pointed out that one of the mechanisms by which the ticks defend themselves from microorganisms is related to the peptides derived from enzymatic cleavage of the haemoglobin ingested by the ticks (Fogaça et al., 1999).

It is interesting to note that concomitant infection with the two Babesia species prevailed in the cattle of both age ranges, in contrast to what is observed for B. microplus females and eggs in which prevailed simple babesial infection. Recently, Paul et al. (2002) detected the existence of interspecific competition between two avian Plasmodium species and observed that this phenomenon occurs during the phase of gamete fertilization still inside the erythrocytes ingested by the mosquitoes. As also observed here, these authors verified that apparently one species does not interfere with the other in vertebrate hosts. Although it may be suspected that some type of competition occurs between Babesia species in a B. microplus tick, future investigations are necessary to confirm this possibility.

According to available epidemiological data, the percentage of female ticks that transmit Babesia spp. to their progeny is low even when they become infected on animals in the acute phase of the disease (Mahoney and Mirre, 1971). In the present study, since DNA was amplified using $20 \mathrm{mg}$ aliquots of eggs, the data presented refer to the percentage of infected egg samples. On this basis, it can be seen that the frequency of egg samples infected with $B$. bigemina $(33.3 \%)$ was significantly higher than that observed for B. bovis $(7.1 \%)$, in agreement with previous observations.

There was no significant difference between the percentages of egg samples infected with $B$. bigemina in samples collected from calves with overt parasitemia (64.6\%-64/99) and those from calves with no parasitemia (52.8\%-67/127). A positive correlation between $B$. bigemina parasitemia in the vertebrate host and the rate of larval infection via feeding adult female ticks was reported by Riek (1964) but was questioned by others (Mahoney and Mirre, 1971; Melendez and Forlano, 1996). The present results show that, with respect to B. bigemina, there was a weak correlation between parasitemia and infection of the tick progeny, and that female ticks engorged on animals with undetectable parasitemia, but PCR-positive, transmit the infection to eggs at relatively high levels.

Despite the high sensitivity and specificity of $\mathrm{PCR} / \mathrm{nPCR}$, the occurrence of false-negative results has been recorded and has been attributed mainly to the presence of polymerase-inhibiting substances in the samples analysed (Hayden et al., 1991; Barker et al., 1994). In the present experiment, although some data could suggest the occurrence of false-negative results in the vertebrate hosts, these results should be interpreted with caution. It was observed that 22 B. microplus females infected with $B$. bigemina had engorged themselves on animals infected only with $B$. bovis (Tables 2 and 3), while only one of the females infected with $B$. bovis originated from an animal infected only with $B$. bigemina. In view of the possibility of vertical transmission exclusively for B. bigemina (Büscher, 1988), it is possible that the percentage of truly false-negative results in vertebrate hosts is lower than that suggested by the data obtained in the present study. On this basis, truly false-negative results seem to be related to the sensitivity of the method more than to the presence of inhibitory substances.

Further possible occurrence of false-negative results is observed when the infection of B. microplus egg samples is analysed in comparison with female tick infection. It was verified that eight egg samples infected with 
B. bigemina were from females in which only B. bovis was detected. Similarly, eight egg samples infected with $B$. bovis originated from female ticks infected with $B$. bigemina. Besides these, negative females gave origin to 16 egg samples infected with $B$. bovis and to 32 infected with $B$. bigemina. In all these cases it is also possible that the false-negative female tick results are related to the detection threshold of the methods, since sporokinetes perform several cycles of sporogony in the eggs, increasing the availability of DNA strands for amplification.

In the present study, DNA amplification techniques verified that in an endemic area the infection rates of the two Babesia species is similar in adult and young cattle, but the transmissibility of each species for ticks varies as a function of the age of the vertebrate hosts.

\section{Acknowledgements}

We thank to Dr Henrique Nunes de Oliveira for the assistance with the statistical analysis of results. Grants for this project was supported by Fundação de Amparo à Pesquisa no Estado de São Paulo (FAPESP-00/09103-7).

\section{References}

Almeria, S., Castellà, J., Ferrer, D., Ortuño, A., Estrada-Peña, A., Gutierrez, J.F., 2001. Bovine piroplasms in minorca (Balearic Islands Spain): a comparison of PCR-based and light microscopy detection. Vet. Parasitol. 99, 249-259.

Araújo, F.R., Madruga, C.R., Almeida, M.A.O., Leal, C.R.B., Miguita, M., 1997. Levantamento sorológico de Babesia bovis e Babesia bigemina no Estado da Bahia pela imunofluorescência indireta e teste de conglutinação rápida. Rev. Bras. Parasitol. Vet. 6, 111-115.

Barker, R.H., Banchongaksorn, T., Courval, J.M., Suwonkerd, W., Rimwungtragoon, K., Wirth, D.F., 1994. Plasmodium falciparum and P. vivax: factors affecting sensitivity and specificity of PCR-based diagnosis of malaria. Exp. Parasitol. 79, 41-49.

Büscher, G., 1988. The infection of various tick species with Babesia bigemina: its transmission and identification. Parasitol. Res. 74, 324-330.

Calder, J.A.M., Reddy, G.R., Chieves, L., Courtney, C.H., Littell, R., Livengood, J.R., Norval, R.A.I., Smith, G., Dame, J.B., 1996. Monitoring Babesia bovis in cattle using PCR-based tests. J. Clin. Microbiol. 34, 2748-2755.

Callow, L.L., 1968. The infection of Boophilus microplus with Babesia bigemina. Parasitology 58, 663-670.

Davey, R.B., 1981. Effects of Babesia bovis on the ovopositional success of the southern cattle tick Boophilus microplus. Ann. Entomol. Soc. Am. $74,331-333$.

Fahrimal, Y., Goff, W.L., Jasmer, D.P., 1992. Detection of Babesia bovis carrier cattle by using polymerase chain reaction amplification of parasite DNA. J. Clin. Microbiol. 30, 1374-1379.

Figueroa, J.V., Chieves, L.P., Johnson, G.S., Buening, G.M., 1992. Detection of Babesia bigemina-infected carriers by polymerase chain reaction amplification. J. Clin. Microbiol. 30, 2576-2582.
Figueroa, J.V., Chieves, L.P., Johnson, G.S., Buening, G.M., 1993. Multiplex polymerase chain reaction based assay for the detection of Babesia bigemina Babesia bovis and Anaplasma marginale DNA in bovine blood. Vet. Parasitol. 50, 69-81.

Fogaça, A.C., Da Silva Jr., P.I., Miranda, M.T.M., Bianchi, A.G., Miranda, A., Ribolla, P.E., Daffre, S., 1999. Antimicrobial activity of a bovine hemoglobin fragment in the tick Boophilus microplus. J. Biol. Chem. 274, 25330-25334.

Friedhoff, K.T., Smith, R.D., 1981. Transmission of Babesia by ticks, in: Ristic, M., Kreier, J.P. (Eds.), Babesiosis. Academic Press, San Diego, pp. 267-321.

Goff, W.L., Johnson, W.C., Tuo, W., Valdez, R.A., Parish, S.M., 2002. Age-related innate immune response in calves to Babesia bovis involves IL-2 induction and IL-10 modulation. Ann. N.Y. Acad. Sci. 969, 164-168.

Guglielmone, A.A., Gaido, A.B., Mangold, A.J., 1996. Light microscopy diagnosis of Babesia bovis and Babesia bigemina kinetes in the haemolymph of artificially infected Boophilus microplus engorged female ticks. Vet. Parasitol. 61, 15-20.

Guglielmone, A.A., Gaido, A.B., Aguirre, D.H., Cafrune, M.M., 1997. Some quantitative aspects of natural babesial infection in the haemolymph of Boophilus microplus engorged female ticks. Parasite 4, 337-341.

Hayden, J.D., Ho, S.A., Hawkey, P.M., Taylor, G.R., Quirke, P., 1991. The promises and pitfalls of PCR. Vet. Med. Microbiol. 2, 129-137.

Hermans, P., Dwinger, R.H., Buening, G.M., Herrero, M.V., 1994. Seasonal incidence and hemoparasite infection rates of Ixodid ticks (Acari: Ixodidae) detached from cattle in Costa Rica. Rev. Biol. Trop. $42,623-632$.

Madruga, C.R., Marques, A.P.C., Araújo, F.R., Miguita, M., Carvalho, C.M.E., Araújo, F.S., Umaki, A.C.S., Crocci, A.J., Queiróz, R.A., 2001. Evaluation of an Elisa for detection of antibodies to Babesia bigemina in cattle and it's application in an epidemiological survey in Brazil. Pesq. Vet. Bras. 21, 72-76.

Mahoney, D.F., Mirre, G.B., 1971. Bovine babesiasis: estimation of infection rates in the tick vector Boophilus microplus (Canestrini). Ann. Trop. Med. Parasitol. 65, 309-317.

Mahoney, D.F., Mirre, G.B., 1977. The selection of larvae of Boophilus microplus infected with Babesia bovis (Syn B. argentina). Res. Vet. Sci. 23, 126-127.

Melendez, R.D., Forlano, M., 1996. Incidence and intensity of Babesia spp. sporokinetes in engorged Boophilus microplus from a dairy herd in Venezuela. Ann. N.Y. Acad. Sci. 791, 148-156.

Morzaria, S., Katende, J., Kairo, A., Nene, V., Musoke, A., 1992. New methods for the diagnosis of Babesia bigemina infection. Mem. Inst. Oswaldo Cruz 87 (Suppl. III), 201-205.

Passos, L.M.F., Bell-Sakyi, L., Brown, C.G.D., 1998. Immunochemical characterization of in vitro culture-derived antigens of Babesia bovis and Babesia bigemina. Vet. Parasitol. 76, 239-249.

Pasvol, G., Weatheral, D.J., Wilson, R.J.M., Smith, D.H., Gilles, H.M., 1976. Fetal haemoglobin and malaria. Lancet 12, 1269-1272.

Paul, R.E.L., Nu, V.A.T., Krettli, A.U., Brey, P.T., 2002. Interespecific competition during transmission of two sympatric malaria parasite species to the mosquito vector. Proc. R. Soc. Lond. B 269, 2551-2557.

Riek, R.F., 1964. The cycle of Babesia bigemina (Smith and Kilborne, 1893 ) in the tick vector Boophilus microplus (Canestrini). Aust. J. Agric. Res. 15, 802-821.

Riek, R.F., 1966. The cycle of Babesia argentina (Lignières, 1903) (Sporozoa: Piroplasmidea) in the tick vector Boophilus microplus (Canestrini). Aust. J. Agric. Res. 17, 247-254.

Ristic, M., Levi, M.G., 1981. A new era of research towards solution of bovine babesiosis, in: Ristic, M., Kreier, J.P. (Eds.), Babesiosis. Academic Press, San Diego, pp. 509-562.

Robert, V., Tchuinkam, T., Mulder, B., Bodo, J.-M., Verhave, J.-P., Carnevale, P., Nagel, R.L., 1996. Effect of sickle cell trait status of the gametocyte carriers of Plasmodium falciparum on infectivity to anophelines. Am. J. Trop. Med. Hyg. 54, 111-113. 
Smeenk, I., Kelly, P.J., Wray, K., Musuka, G., Trees, A.J., Jongejan, F., 2000. Babesia bovis and Babesia bigemina DNA detected in cattle and ticks from Zimbabwe by polymerase chain reaction. J. S. Afr. Vet. Assoc. 71, 21-24.

Vidotto, O., Andrade, G.M., Amaral, C.H.S., Barbosa, C.S., Freire, R.I., Rocha, M.A., Vidotto, M.C., 1997. Freqüência de anticorpos contra Babesia bigemina B. bovis e Anaplasma marginale em rebanhos bovinos na região de Londrina, Paraná. Arq. Bras. Med. Vet. Zootec 49, 655-659.
Wagner, G., Cruz, D., Holman, P., Waghela, S., Perrone, J., Shompole, S., Rurangirwa, F., 1992. Non-immunologic methods of diagnosis of babesiosis. Mem. Inst. Oswaldo Cruz 87 (Suppl. III), 193-199.

Yeruham, I., Hadani, A., Galker, F., 2001. The effect of the ovine host parasitaemia on the development of Babesia ovis (Babes, 1892) in the tick Rhipicephalus bursa (Canestrini and Fanzago, 1877). Vet. Parasitol. 96, 195-202. 